Artigo Original

Original Article

Juliana Ceglio Monteiro ${ }^{1}$ (C)

Glaucya Madazio ${ }^{1}$

Claudia Pacheco ${ }^{1}$

Mara Behlau ${ }^{1}$ (1)

Descritores

Avaliação em Saúde

Canto

Fonoaudiologia

Música

Voz

Keywords

Health Evaluation

Singing

Speech, Language and Hearing

Sciences

Music

Voice

Endereço para correspondência: Juliana Ceglio Monteiro

Centro de Estudos da Voz - CEV

Rua Machado Bittencourt, $61,10^{\circ}$ andar,

Vila Clementino, São Paulo (SP), Brasil, CEP: 04044-905.

E-mail: jucm5@hotmail.com

Recebido em: Setembro 24, 2018

\section{Principais fatores que levam os professores de canto popular a buscar ajuda fonoaudiológica}

\author{
Main reasons that lead popular-music singing \\ teachers to seek speech-language pathology \\ assistance for their students
}

\begin{abstract}
RESUMO
Objetivo: Identificar os fatores que influenciam a decisão do professor de canto em solicitar ajuda fonoaudiológica para seus alunos. Método: Participaram do presente estudo 48 professores de canto popular, de ambos os sexos, com média de idade de 37,96 anos. Os participantes responderam via SurveyMonkey um questionário elaborado pelos pesquisadores, composto por dez perguntas, com respostas fechadas. Estas perguntas referiam-se aos motivos pelos quais o professor de canto popular busca ajuda fonoaudiológica e sobre o conhecimento desses professores a respeito da rouquidão persistente ser um sintoma de risco que identifique outro tipo de lesão na laringe. Resultados: Os resultados indicaram que professores de canto buscam ajuda fonoaudiológica na presença de queixa de voz rouca e dificuldade de articulação. Para os professores avaliados, a queixa de cansaço vocal não foi fator determinante para o encaminhamento fonoaudiológico. Houve maior proporção de professores de canto que não sabiam que queixa de rouquidão por mais do que quinze dias pode ser sinal de lesão maligna de laringe. Não houve influência das variáveis idade e tempo de prática de ensino de canto dos professores de canto popular no encaminhamento para Fonoaudiólogos. Conclusão: A maior parte dos professores de canto avaliados busca ajuda fonoaudiológica quando o aluno apresenta queixa de voz rouca e dificuldade de articulação dos sons da fala.
\end{abstract}

\begin{abstract}
Purpose: To identify the parameters that influences the decision of singing teachers to seek speech-language pathology (SLP) assistance for their students. Methods: The study sample comprised 48 popular-music singing teachers, male and female, aged 37.96 years on average. The participants responded to a 10 closed-question questionnaire prepared by the researchers via the SurveyMonkey platform. The questions referred to the reasons why singing teachers seek SLP assistance, as well as to the knowledge of these teachers regarding chronic hoarseness as a risk symptom to identify other lesions in the larynx. Results: Singing teachers seek SLP assistance for their students in the presence of hoarseness complaints and impaired speech sound articulation. The singing teachers assessed did not consider vocal tiredness complaint as a determining factor for referral to SLP evaluation. Most study participants were not aware that a hoarseness complaint for over 15 days can be indicative of larynx tumor. There was no influence of the variables age and time of professional experience in the referral to SLP assistance. Conclusion: Most of the singing teachers who participated in this study sought SLP assistance for their students when they presented hoarseness complaints and impaired speech sound articulation.
\end{abstract}

Trabalho realizado no Centro de Estudos da Voz - CEV - São Paulo (SP), Brasil.

Fonte de financiamento: nada a declarar.

Conflito de interesses: nada a declarar. 


\section{INTRODUÇÃO}

O canto é uma forma de expressão vocal utilizada pela humanidade e, de modo profissional, por inúmeros artistas. Esses artistas precisam realizar ajustes laríngeos de maior ou menor complexidade, ter um bom controle do fluxo aéreo, fazer uso das cavidades de ressonância e dos órgãos fonoarticulatórios para ter expressividade na emissão ${ }^{(1)}$, além do contato com a audiência.

O estilo de canto impacta a interpretação de uma canção ${ }^{(2)}$. Sendo assim, fatores como técnica, treinamento e demanda vocal, além da percepção do artista sobre sua própria voz, costumam ser diferentes, dependendo do estilo ou gênero de canto adotado ${ }^{(2,3)}$.

Cantores populares, foco deste estudo, em geral, começam sua carreira profissional por gostarem de cantar e serem atraídos pela música desde criança, frequentemente desenvolvendo suas habilidades de modo intuitivo. A partir daí, muitas etapas são percorridas até que se tornem profissionais e tenham uma carreira reconhecida pelo mercado musical ${ }^{(1,4,5)}$. Além disso, cantores populares são solicitados a cantar vários estilos musicais em uma mesma apresentação, para atender à demanda do contratante e agradar ao público ${ }^{(6)}$, o que representa um desafio fisiológico e técnico. Desta forma, é evidente que necessitam de grande flexibilidade vocal e habilidade de interpretação de canto diferenciadas ${ }^{(6)}$, o que pode representar um verdadeiro desafio funcional.

$\mathrm{O}$ fato de o canto exigir diversos ajustes laríngeos pode favorecer o aparecimento de sintomas e sinais de distúrbios vocais, principalmente relacionados ao uso inadequado ou abusivo da $v z^{(1,7)}$. Isso faz com que os cantores sejam uma população de risco para desenvolver uma disfonia, o que já é comprovado pela grande ocorrência de distúrbios vocais nessa população ${ }^{(8,9)}$.

Estudos anteriores indicam risco para o desenvolvimento de distúrbios vocais nessa população. Um trabalho de caracterização vocal de cantores populares brasileiros mostrou grande ocorrência de tipo respiratório superior, incoordenação pneumofonoarticulatória, ressonância laringofaríngea, articulação imprecisa e ataque vocal brusco $^{(1)}$. Outro estudo avaliou a voz dos cantores da noite do estilo denominado "brega" e mostrou predominância de frequência aguda, intensidade elevada, ataque vocal brusco, registro modal do tipo cabeça e ressonância equilibrada com compensação nasal na voz cantada, sendo que, com exceção do ataque vocal, as demais características não apareceram na voz falada dos mesmos cantores ${ }^{(10)}$.

Tais aspectos em conjunto com as necessidades profissionais dos cantores populares, fazem com que o abuso e mau uso vocal sejam mais frequentes nessa modalidade de canto $^{(1,6)}$, apesar de muitas vezes os profissionais terem a consciência do risco vocal a que se submetem. Apesar de cantores populares algumas vezes não terem a carreira impactada por distúrbios vocais, eles pertencem à elite de profissionais da voz, o que faz com que pequenos desvios vocais já possam impactar os aspectos profissionais, pessoais (físico, mental, social, emocional e comunicativo) e financeiros ${ }^{(2)}$. Dessa forma, é de extrema importância a manutenção da saúde vocal nessa população.

Cantores comumente buscam primeiro o professor de canto $^{(9,11)}$, na presença de alguma queixa ou dúvida relacionada a voz, e, posteriormente, procuram profissionais da saúde, como
Médicos e Fonoaudiólogos ${ }^{(12)}$. Desta forma, é essencial que o professor de canto tenha preparo específico para saber identificar e diferenciar as queixas que possam indicar problemas de saúde vocal e que extrapolem o campo de atuação da pedagogia vocal, para realizar o encaminhamento necessário corretamente e ser um parceiro na saúde de seus alunos.

Embora ainda não existam normas que estabeleçam em que momento a atuação da pedagogia vocal necessita de outros profissionais para apoio de sua conduta, sabe-se que a interdisciplinaridade entre Fonoaudiólogos, Médicos Otorrinolaringologistas e professores de canto, no atendimento de cantores, pode auxiliar o desenvolvimento vocal desses profissionais. O campo de atuação do Fonoaudiólogo, no que se refere ao atendimento de problemas vocais, pressupõe, após diagnóstico otorrinolaringológico, avaliação e terapia ou treinamento vocal, sendo necessária a graduação deste profissional em Fonoaudiologia e uma desejada especialização em voz. Na pedagogia vocal, não são claros os critérios de certificação e currículo em relação à saúde vocal, ciência vocal e aplicações clínicas/médicas, bem como pré-requisitos para a atuação, o que faz com que o conhecimento e os métodos de treinamento educacionais de canto ainda sejam heterogêneos ${ }^{(13)}$.

Além disso, apesar de os professores de canto considerarem importante a educação em saúde vocal, muitos não têm conhecimento sobre fisiologia, anatomia, higiene e funções vocais, e principalmente sobre patologias vocais ${ }^{(9)}$. Fatores como limitação de currículo, falta de recursos financeiros e falta de disponibilidade foram relatados como barreiras para que os professores de canto compreendessem e fornecessem melhores informações sobre saúde vocal aos alunos ${ }^{(9)}$. Isso faz com que, muitas vezes, apesar da não evolução vocal do aluno, os professores de canto não saibam identificar se o motivo seria uma questão pedagógica ou fonoaudiológica, fazendo com que a atuação interdisciplinar entre o professor de canto e o Fonoaudiólogo não aconteça ${ }^{(13)}$.

Conhecer os fatores que levam o professor de canto popular a procurar o Fonoaudiólogo pode contribuir para delimitar o foco de ações que visem à conscientização da importância do trabalho interdisciplinar para otimizar os resultados obtidos com o cantor popular.

Dessa forma, o objetivo do presente estudo foi identificar os parâmetros que influenciam a decisão do professor de canto em buscar ajuda fonoaudiológica para seus alunos.

\section{MÉTODO}

Trata-se de uma pesquisa observacional, transversal e quantitativa. A pesquisa foi aprovada pelo Comitê de Ética em Pesquisa (parecer 2.668.237).

Os participantes do presente estudo foram recrutados pessoalmente, por meio da rede de contato dos pesquisadores e online via SurveyMonkey. Todos receberam uma explicação sobre a pesquisa e foram solicitados a assinar o Termo de Consentimento Livre e Esclarecido.

Para a seleção dos participantes, foram estabelecidos critérios de inclusão e exclusão. Foram incluídos professores de canto popular de ambos os sexos, com idade a partir de 18 anos. 
Foram excluídos professores de canto com menos de 3 anos de experiência. Para isso, todos responderam a um questionário amostral sobre dados profissionais e de identificação (Apêndice A).

Responderam o questionário 50 sujeitos, dos quais, dois foram excluídos devido aos critérios de exclusão. Dessa forma, a amostra do presente estudo foi composta por 48 professores de canto popular, com média de idade de 37,96 anos, que ensinavam canto há, em média, 13 anos.

Os participantes selecionados responderam a um questionário elaborado pelos pesquisadores que constava de dez perguntas com respostas fechadas, baseadas na prática profissional na área de canto. Das dez perguntas, nove eram referentes aos fatores que influenciam o professor de canto popular a realizar o encaminhamento do aluno ao Fonoaudiólogo, e uma questão era relativa ao conhecimento desses professores a respeito de a rouquidão persistente ser um sintoma de risco para o desenvolvimento de tumor de laringe. Para cada pergunta, os professores foram orientados a assinalar sim ou não.

Os dados referentes à idade e tempo de prática de ensino de canto respondidos no protocolo de seleção também foram utilizados na análise de dados.

Os dados foram analisados por meio de estatística descritiva e inferencial utilizando-se o software Statistica versão $13.0^{(14)}$.

As variáveis quantitativas discretas idade e tempo de prática de ensino de canto foram analisadas descritivamente por média, desvio padrão, mediana, primeiro e terceiro quartil. As variáveis qualitativas nominais referentes aos fatores que fazem com que os professores de canto encaminhem o aluno para o Fonoaudiólogo foram analisadas descritivamente por frequência relativa e porcentagem.

O nível de significância adotado para todas as análises estatísticas inferenciais foi de $5 \%(\mathrm{p}<0,05)$. Para a estatística inferencial, a normalidade das variáveis quantitativas foi testada por meio do teste Shapiro Wilk e todas obtiveram distribuição não normal.

A análise e comparação da proporção das variáveis qualitativas foram realizadas com o Teste de Duas Proporções.

A análise e comparação dos resultados das variáveis quantitativas em função das variáveis qualitativas foram realizadas com o teste não paramétrico Teste Mann-Whitney.

\section{RESULTADOS}

A Tabela 1 indica que a proporção de professores de canto popular que buscam ajuda fonoaudiológica para seus alunos foi significativamente maior na presença de queixa de voz rouca $(p<0,001)$ e dificuldade de articulação $(p=0,026)$. Quanto ao item queixa de cansaço ao falar por algumas horas seguidas, observou-se que a maior parte dos professores de canto não encaminha seus alunos ao Fonoaudiólogo quando tal aspecto é a principal demanda $(\mathrm{p}=0,004)$. Observou-se ainda que houve

Tabela 1. Análise e comparação da proporção de ocorrência dos fatores que levam os professores de canto a buscarem ajuda fonoaudióloga

\begin{tabular}{|c|c|c|c|}
\hline Variáveis e categorias & $\mathrm{n}$ & $\%$ & p-valor \\
\hline \multicolumn{4}{|l|}{ Dificuldade em agudos } \\
\hline Sim & 27 & 55,10 & \multirow[t]{2}{*}{0,481} \\
\hline Não & 22 & 44,90 & \\
\hline \multicolumn{4}{|l|}{ Dificuldade respiratória } \\
\hline $\operatorname{Sim}$ & 22 & 44,90 & \multirow[t]{2}{*}{0,481} \\
\hline Não & 27 & 55,10 & \\
\hline \multicolumn{4}{|l|}{ Queixa de voz rouca } \\
\hline $\operatorname{Sim}$ & 43 & 87,76 & \multirow[t]{2}{*}{$<0,001^{*}$} \\
\hline Não & 6 & 12,24 & \\
\hline \multicolumn{4}{|l|}{ Dificuldade de articulação } \\
\hline Sim & 33 & 67,35 & \multirow[t]{2}{*}{$0,026^{*}$} \\
\hline Não & 16 & 32,65 & \\
\hline \multicolumn{4}{|l|}{ Queixa de falta de projeção } \\
\hline $\operatorname{Sim}$ & 19 & 38,78 & \multirow[t]{2}{*}{0,132} \\
\hline Não & 30 & 61,22 & \\
\hline \multicolumn{4}{|l|}{ Queixa de refluxo } \\
\hline Sim & 28 & 57,14 & \multirow[t]{2}{*}{0,479} \\
\hline Não & 21 & 42,86 & \\
\hline \multicolumn{4}{|c|}{ Queixa de cansaço ao falar por algumas horas seguidas } \\
\hline $\operatorname{Sim}$ & 13 & 26,53 & \multirow[t]{2}{*}{$0,004^{*}$} \\
\hline Não & 36 & 73,47 & \\
\hline \multicolumn{4}{|c|}{ Só consegue cantar em alta intensidade } \\
\hline Sim & 26 & 53,06 & \multirow[t]{2}{*}{0,670} \\
\hline Não & 23 & 46,94 & \\
\hline \multicolumn{4}{|c|}{ Pigarro, sensação de secura ou algum outro desconforto na garganta } \\
\hline Sim & 19 & 38,78 & \multirow[t]{2}{*}{0,132} \\
\hline Não & 30 & 61,22 & \\
\hline \multicolumn{4}{|c|}{ Você sabia que queixa de rouquidão há mais de quinze dias pode ser sinal de tumor } \\
\hline Sim & 14 & 28,57 & \multirow[t]{2}{*}{$0,008^{\star}$} \\
\hline Não & 35 & 71,43 & \\
\hline
\end{tabular}

Teste de Duas Proporções; ${ }^{*} \mathrm{p}<0,05$

Legenda: $\mathrm{n}=$ número de participantes; $\%$ = porcentagem de participantes 
Tabela 2. Análise e comparação dos fatores que levam os professores de canto a buscarem ajuda fonoaudióloga, em função das variáveis idade e tempo de prática de ensino de canto

\begin{tabular}{|c|c|c|c|c|c|c|c|}
\hline \multirow{2}{*}{ Variáveis e categorias } & \multicolumn{3}{|c|}{ Sim } & \multicolumn{3}{|c|}{ Não } & \multirow{2}{*}{$\mathrm{p}$-valo } \\
\hline & Média & DP & Mediana & Média & DP & Mediana & \\
\hline \multicolumn{8}{|l|}{ Dificuldade em agudos } \\
\hline Idade & 37,15 & 6,87 & 36,00 & 38,95 & 8,69 & 35,00 & 0,672 \\
\hline Tempo de prática de ensino de canto & 12,96 & 7,96 & 11,00 & 13,23 & 7,93 & 11,00 & 0,895 \\
\hline \multicolumn{8}{|l|}{ Dificuldade respiratória } \\
\hline Idade & 39,64 & 7,88 & 38,00 & 36,59 & 7,44 & 35,00 & 0,138 \\
\hline Tempo de prática de ensino de canto & 15,14 & 8,61 & 13,50 & 11,41 & 6,92 & 10,00 & 0,125 \\
\hline \multicolumn{8}{|l|}{ Queixa de voz rouca } \\
\hline Idade & 37,91 & 7,51 & 36,00 & 38,33 & 9,83 & 36,50 & 0,818 \\
\hline Tempo de prática de ensino de canto & 12,81 & 7,49 & 11,00 & 15,00 & 10,84 & 15,00 & 0,690 \\
\hline \multicolumn{8}{|l|}{ Dificuldade de articulação } \\
\hline Idade & 39,12 & 8,06 & 38,00 & 35,56 & 6,53 & 35,00 & 0,097 \\
\hline Tempo de prática de ensino de canto & 14,15 & 7,97 & 12,00 & 10,88 & 7,41 & 10,00 & 0,154 \\
\hline \multicolumn{8}{|l|}{ Queixa de falta de projeção } \\
\hline Idade & 38,68 & 8,74 & 37,00 & 37,50 & 7,10 & 35,00 & 1,000 \\
\hline Tempo de prática de ensino de canto & 12,11 & 8,65 & 10,00 & 13,70 & 7,41 & 12,50 & 1,000 \\
\hline \multicolumn{8}{|l|}{ Queixa de refluxo } \\
\hline Idade & 38,32 & 7,46 & 37,50 & 37,48 & 8,19 & 35,00 & 0,453 \\
\hline Tempo de prática de ensino de canto & 14,04 & 8,44 & 11,50 & 11,81 & 7,03 & 10,00 & 0,434 \\
\hline \multicolumn{8}{|c|}{ Queixa de cansaço ao falar por algumas horas seguidas } \\
\hline Idade & 39,08 & 8,71 & 36,00 & 37,56 & 7,41 & 35,50 & 0,759 \\
\hline Tempo de prática de ensino de canto & 13,25 & 7,02 & 11,5 & 12,62 & 10,17 & 10,00 & 0,419 \\
\hline \multicolumn{8}{|l|}{ Só consegue cantar em alta intensidade } \\
\hline Idade & 39,15 & 8,76 & 37,00 & 36,61 & 6,24 & 35,00 & 0,520 \\
\hline Tempo de prática de ensino de canto & 14,39 & 8,07 & 15,00 & 11,92 & 7,65 & 10,00 & 0,231 \\
\hline \multicolumn{8}{|c|}{ Pigarro, sensação de secura ou algum outro desconforto na garganta } \\
\hline Idade & 38,74 & 8,84 & 37,00 & 37,47 & 7,02 & 35,00 & 0,557 \\
\hline Tempo de prática de ensino de canto & 15,37 & 8,77 & 13,00 & 11,63 & 7,00 & 10,00 & 0,127 \\
\hline \multicolumn{8}{|c|}{ Você sabia que queixa de rouquidão há mais de quinze dias pode ser sinal de tumor } \\
\hline Idade & 42,07 & 8,19 & 41,00 & 36,31 & 6,97 & 35,00 & 1,000 \\
\hline Tempo de prática de ensino de canto & 11,89 & 7,02 & 10,00 & 16,07 & 9,28 & 15,00 & 1,000 \\
\hline
\end{tabular}

Teste de Mann-Whitney; $p<0,05$

Legenda: DP = desvio padrão

maior proporção de professores de canto que não sabiam que queixa de rouquidão por mais do que quinze dias pode ser sinal de tumor $(\mathrm{p}=0,008)$.

A Tabela 2 indica que não houve influência das variáveis idade e tempo de prática de ensino de canto na resposta dos professores de canto sobre os fatores que fazem com que eles encaminhem o aluno para o Fonoaudiólogo.

\section{DISCUSSÃO}

A maioria dos cantores populares inicia a carreira profissional sem o conhecimento sobre técnicas do canto, apenas com base no desejo e dom de cantar ${ }^{(4)}$, de modo mais ou menos intuitivo, apesar da necessidade profissional de flexibilidade vocal ${ }^{(6)}$. Além disso, alguns hábitos, fatores do ambiente de trabalho e da demanda fazem com que eles tenham maior risco para desenvolver distúrbios vocais ${ }^{(9)}$, embora nem sempre desvios vocais impliquem limitações no canto popular. $\mathrm{Na}$ presença de queixa relacionada à saúde vocal, cantores populares normalmente recorrem primeiro ao professor de canto ${ }^{(9)}$, porém, muitas vezes, o pedagogo vocal não tem conhecimento suficiente para identificar se a queixa está relacionada à técnica ou é um sintoma de patologia vocal. Diante da ausência de informações sobre os fatores que levam o professor de canto a buscar ajuda do Fonoaudiólogo na atuação com o cantor, o presente estudo buscou levantar quais os principais fatores que influenciam os professores de canto popular a buscar ajuda fonoaudiológica.

Os participantes do presente estudo eram adultos e possuíam tempo médio de atuação como professores de canto popular de 13 anos. Esses dados foram semelhantes aos de outros estudos fonoaudiológicos com professores de canto ${ }^{(15,16)}$. O atual levantamento indicou que a maioria dos professores de canto popular tem formação profissional na área de música, o que pode ser um dos fatores que contribui para o início mais tardio da atuação na área. Os professores de canto popular ficam atrás apenas dos professores de canto erudito, que costumam ser mais velhos, ter mais tempo de experiência e maior frequência de profissionais graduados em Música ${ }^{(15)}$. 
Houve uma proporção significativamente maior de professores que encaminham o aluno para o Fonoaudiólogo apenas quando há indícios de queixa de voz rouca (Tabela 1) e dificuldade de articulação dos sons (Tabela 1). De modo geral, a rouquidão, queixa mais frequente em cantores populares ${ }^{(17)}$, é o sintoma de alteração vocal mais comum. Na maioria dos casos, ele está relacionado ao mau uso vocal, abuso vocal ou alterações de vias aéreas superiores ${ }^{(18)}$. Nos profissionais da voz que pertencem à elite vocal ${ }^{(2)}$, como os cantores, essa alteração pode limitar a atuação profissional, necessitando em alguns casos de uma resolução imediata do problema ${ }^{(2)}$.

Acredita-se que difundir o conhecimento sobre a possível etiologia e as consequências, no caso de não resolução do problema, é fundamental para a saúde vocal do cantor. Neste estudo, a maior parte dos profissionais avaliados referiram encaminhar o aluno para o Fonoaudiólogo quando existe a queixa. Além disso, trata-se de uma queixa que comumente não pode ser resolvida pelo professor de canto, por necessitar de uma intervenção medicamentosa ou de terapia vocal, dependendo da etiologia.

Com relação à articulação dos sons, acredita-se que esse foi um dos fatores com maior proporção de professores que referem encaminhar para o Fonoaudiólogo porque no canto popular as palavras e a articulação têm um papel fundamental ${ }^{(17)}$. A precisão articulatória é importante para que o ouvinte compreenda a mensagem das frases musicais. A articulação bem definida, associada à projeção da voz, torna o ajuste vocal mais eficiente para a performance em ambientes maiores ${ }^{(17)}$. Tais recursos são essenciais para cantores amadores e precisam ser resolvidos logo que os alunos ingressem nas aulas de canto, para que tenham bom desempenho com a voz cantada. Este fato pode justificar o motivo de os professores de canto considerarem alterações articulatórias como fatores que necessitam do encaminhamento para o Fonoaudiólogo.

A proporção de professores que encaminham o aluno para o Fonoaudiólogo quando este refere queixa de cansaço ao falar por algumas horas seguidas foi pequena (Tabela 1). Isso significa que, ao contrário do esperado, a maioria dos professores de canto popular não encaminha o aluno para avaliação fonoaudiológica quando identifica queixa de cansaço ao falar por algumas horas seguidas, talvez por acreditar que essa manifestação seja inerente às fases iniciais do aprendizado de canto. Cantores necessitam de exatidão na emissão de notas e de ajustes vocais específicos que devem ser executados de modo a não causar sobrecarga para o aparelho fonador ${ }^{(19)}$. Além disso, muitos cantores desempenham outras atividades vocais, que, somadas ao canto, contribuem para o desgaste vocal dessa população ${ }^{(19)}$, o que merece ser adequadamente avaliado. Acredita-se que o professor de canto possa achar natural que o cantor refira cansaço após o uso da voz por um longo período de tempo. Apesar disso, sabe-se que a queixa de cansaço vocal comumente está relacionada à sobrecarga, que pode ser decorrente de abuso e mau uso da voz por falta de conhecimento sobre saúde vocal e sobre os ajustes adequados para fala ou canto, ou ainda, decorrente da falta de resistência necessária para a demanda vocal exigida ${ }^{(20)}$. Nesse sentido, o professor de canto também parece desconhecer a atuação fonoaudiológica na adequação da voz do cantor à demanda, mesmo sendo uma atividade desempenhada pelo Fonoaudiólogo que é de fundamental importância para a longevidade vocal do cantor, bem como para a prevenção de distúrbios vocais decorrentes do uso vocal incorreto ${ }^{(21)}$. Nesse sentido, observa-se a necessidade de que os professores de canto sejam orientados pelos Fonoaudiólogos, para que esse encaminhamento ocorra. A atuação conjunta do Fonoaudiólogo e do professor de canto poderia trazer benefícios para os cantores, principalmente no que tange aos cuidados com a voz e à resistência vocal ${ }^{(22)}$, cuja falta está diretamente relacionada à queixa de sobrecarga e cansaço vocal. Além dos benefícios diretos aos próprios cantores, a atuação conjunta de profissionais, que têm como base de sua formação, respectivamente, a saúde e a pedagogia vocal, traz benefícios aos próprios envolvidos, que passam a ser mais sensíveis às áreas de atuação própria e do outro, agindo de forma integrada. Considerando que a atuação conjunta é complementar, seria possível atender à demanda e realizar uma preparação adequada e completa do cantor popular, de acordo com sua demanda e necessidade profissional.

A literatura relata a importância de uma atuação interdisciplinar entre professores de canto e Fonoaudiólogos ${ }^{(13,22)}$. Porém, para isso, eles referem que há necessidade de compreender as práticas interdisciplinares a partir da teoria, ou seja, da formação do profissional, e depois avançar para ações guiadas pela demanda da prática ${ }^{(22)}$. Nesse sentido, os resultados do presente estudo parecem indicar que os professores de canto têm pouco conhecimento sobre a atuação fonoaudiológica com os alunos de canto popular.

Cantores costumam procurar primeiro o professor de canto para aconselhar-se sobre uma queixa vocal, ao invés de buscar auxílio de um profissional da saúde ${ }^{(9)}$. Houve maior proporção de professores de canto que não sabem que queixa de rouquidão há mais de quinze dias pode ser sinal de lesão laríngea, benigna ou maligna (Tabela 1). Esse dado é importante, visto que o foco desses profissionais muitas vezes está voltado às questões mais específicas de técnica vocal, podendo não atentar para uma queixa de rouquidão prolongada como uma possibilidade de risco à saúde de seu aluno. Apesar de as queixas relacionadas à voz cantada poderem trazer prejuízos profissionais mais imediatos, a queixa de rouquidão deve ser valorizada pelo professor de canto, especialmente se ela é de longa data. Embora, na maioria das vezes, a queixa de rouquidão represente uma alteração benigna na laringe, nos casos em que ela persiste, deve-se investigar se essa é uma questão estilística preferida pelo cantor ou se representa um importante risco vocal. Além disso, hábitos negativos, como o tabagismo e o etilismo ${ }^{(5)}$, são frequentes em cantores populares e aumentam o risco de comprometimento de saúde nessa população. Nesses casos, o diagnóstico e o tratamento precoce são essenciais para o paciente ${ }^{(23)}$. Tais dados alertam para a necessidade de valorização, por parte do professor de canto popular, das queixas relacionadas às alterações vocais, como a rouquidão persistente, e a necessidade de encaminhamento diante dessa queixa.

Apesar de muitos professores de canto popular terem formação diversificada, principalmente na área de música ${ }^{(15)}$ e artes, sabe-se que não há uma padronização no treinamento de pedagogia vocal, o que faz com que conteúdos relacionados 
à saúde e reabilitação vocal não sejam conhecidos por todos, visto que o foco da pedagogia vocal é mais voltado para o aspecto artístico ${ }^{(13)}$. A necessidade de adequação da formação em pedagogia vocal para que o professor esteja preparado para atuar em conjunto com o Fonoaudiólogo já foi destacada anteriormente pela literatura, que inclui revisão atual sobre as oportunidades de formação no campo de reabilitação da voz cantada para Fonoaudiólogos, performers e pedagogos vocais ${ }^{(13)}$.

Das dez perguntas do questionário utilizado no estudo, nove eram referentes aos fatores que influenciam o professor de canto popular a realizar o encaminhamento do aluno ao Fonoaudiólogo. Dessas, em seis delas, não houve diferença na proporção de professores de canto que consideravam e que não consideravam a ocorrência dessa queixa como um fator que os levaria a buscar ajuda Fonoaudiológica. Apesar de sem diferença, esse resultado é relevante, visto que todas essas queixas podem ser indicativas de risco vocal, sendo ainda por sobrecarga, ou decorrente de um quadro disfônico já instalado. Esses dados corroboram os demais e apontam para a falta de informação dos professores de canto sobre a atuação Fonoaudiológica com cantores $^{(9)}$.

Diversos fatores são levantados pela literatura como justificativa para a falta de conhecimento e informação dos professores de canto sobre saúde vocal, dentre os quais destacam-se o foco do currículo dos cursos de formação ser essencialmente musical, falta de recursos financeiros e de disponibilidade de tempo que possibilitem ampliação da formação profissional ${ }^{(9)}$. Considerando o fato de que cantores costumam ter queixas semelhantes ${ }^{(19)}$, acredita-se que a ampliação do conhecimento do professor de canto sobre saúde vocal poderia fazer com que ele compreendesse melhor o significado de cada queixa vocal, e assim conseguir identificar quais seriam motivo de encaminhamento do aluno para o Fonoaudiólogo.

A idade (Tabela 2) e o tempo de prática de ensino de canto (Tabela 2) não são fatores de influência no encaminhamento de alunos para os Fonoaudiólogos, por parte dos professores de canto. Os dados indicam que o principal fator que parece influenciar a falta de encaminhamento dos alunos de professores de canto popular para o Fonoaudiólogo é a falta de conhecimento sobre saúde vocal e sobre a atuação fonoaudiológica na área da voz cantada. Conforme mencionado anteriormente, tal carência parece estar relacionada, principalmente, ao currículo com ênfase na perspectiva artística e sem um critério claro de certificação e currículo em relação à saúde vocal, ciência vocal e aplicações clínicas/médicas na pedagogia vocal ${ }^{(13)}$, pré-requisitos para a atuação profissional ${ }^{(9,13)}$.

Não foram encontrados outros estudos que tenham levantado os fatores que levam professores de canto a solicitarem ajuda fonoaudiológica. Os benefícios da atuação conjunta do Fonoaudiólogo e dos professores de canto para aqueles que fazem uso da voz cantada é conhecida, nacional e internacionalmente ${ }^{(22)}$. Apesar disso, esse parece ser um tema que merece maiores esforços de ambos os profissionais, visando aumentar a troca de informações e o conhecimento acerca da atuação conjunta, em prol de um melhor resultado vocal para o público-alvo, que são os cantores populares.

\section{CONCLUSÃO}

$\mathrm{O}$ estudo descrito mostrou que os professores de canto popular procuram ajuda fonoaudiológica principalmente perante a presença de queixa vocal e dificuldade na articulação dos sons da fala, não sendo valorizados outros fatores que podem comprometer a saúde do cantor e a longevidade de sua carreira.

\section{REFERÊNCIAS}

1. Lopes W, Lima I. Características vocais de cantores populares da cidade de João Pessoa. Rev Bras Ciências da Saúde. 2014;18(1):21-6. http://dx.doi. org/10.4034/RBCS.2014.18.01.03.

2. Moreti F, Rocha C, Borrego MCM, Behlau M. Desvantagem vocal no canto: análise do protocolo Índice de Desvantagem para o Canto Moderno - IDCM. Rev Soc Bras Fonoaudiol. 2011;16(2):146-51. http://dx.doi.org/10.1590/ S1516-80342011000200007.

3. Pestana PM, Vaz-Freitas S, Manso MC. Prevalence of voice disorders in singers: systematic review and meta-analysis. J Voice. 2017;31(6):722-7. http://dx.doi.org/10.1016/j.jvoice.2017.02.010. PMid:28342677.

4. Oliveira IB. A educação vocal nos meios de comunicação e arte: a voz cantada. In: Ferreira LP, Oliveira IB, Quinteiro EA, Morato EM, editores. Voz profissional: o profissional da voz. Carapicuiba: Pró-Fono; 1995, pp. 33-43.

5. Dassie-Leite AP, Duprat AC, Busch R. A comparison between vocal habits of lyric and popular singers. Rev CEFAC. 2011;13(1):123-31. http://dx.doi. org/10.1590/S1516-18462010005000118.

6. Silva MMA, Campioto AR. Atendimento fonoaudiológico a cantores populares. In: Ferreira LP, Oliveira IB, Quinteiro EA, Morato EM, editores. Voz profissional: o profissional da voz. Carapicuiba: Pró-Fono; 1995, pp. 67-90.

7. Behlau M, Madazio G, Rehder M, Azevedo R, Ferreira AE. Voz profissional: aspectos gerais da atuação fonoaudiológica. In: Behlau M, editor. Voz: o livro do especialista. São Paulo: Revinter; 2005, pp. 287-367.

8. Phyland DJ, Oates J, Greenwood KM. Self-reported voice problems among three groups of professional singers. J Voice. 1999;13(4):602-11. http:// dx.doi.org/10.1016/S0892-1997(99)80014-9. PMid:10622525.

9. Latham K, Messing B, Bidlack M, Merritt S, Zhou X, Akst LM. Vocal health education and medical resources for graduate-level vocal performance students. J Voice. 2017;31(2):251.e1-7. http://dx.doi.org/10.1016/j. jvoice.2016.07.011. PMid:27567393.

10. Silva EGF, Luna CLC. Análise perceptivo-auditiva de parâmetros vocais em cantores da noite do estilo musical brega da cidade do Recife. Rev CEFAC. 2009;11(3):457-64. http://dx.doi.org/10.1590/S1516-18462009000300013.

11. Braun-Janzen C, Zeine L. Singers' interest and knowledge levels of vocal function and dysfunction: survey findings. J Voice. 2009;23(4):470-83. http://dx.doi.org/10.1016/j.jvoice.2008.01.001. PMid:18468844.

12. Petty BE. Health information-seeking behaviors among classically trained singers. J Voice. 2012;26(3):330-5. http://dx.doi.org/10.1016/j. jvoice.2011.05.009. PMid:21865009.

13. Gerhard J. A review of training opportunities for singing voice rehabilitation specialists. J Voice. 2016;30(3):329-33. http://dx.doi.org/10.1016/j. jvoice.2015.03.020. PMid:26025617.

14. StatSoft Inc. Statistica 13.0. Tulsa

15. Sousa JM, Andrada e Silva MA, Ferreira LP. O uso de metáforas como recurso didático no ensino do canto : diferentes abordagens. Rev Soc Bras Fonoaudiol. 2010;15(3):317-28. http://dx.doi.org/10.1590/S151680342010000300003 .

16. Gava W Jr, Ferreira LP, Andrada e Silva MA. Apoio respiratório na voz cantada: perspectiva de professores de canto e Fonoaudiólogos. Rev CEFAC. 2010;12(4):551-62. http://dx.doi.org/10.1590/S1516-18462010005000047.

17. Zimmer V, Cielo CA, Ferreira FM. Comportamento vocal de cantores populares. Rev CEFAC. 2012;14(2):298-307. http://dx.doi.org/10.1590/ S1516-18462011005000101. 
18. Ferreira LP, Santos JG, Lima MFB. Sintoma vocal e sua provável causa: levantamento de dados em uma população. Rev CEFAC. 2009;11(1):110-8. http://dx.doi.org/10.1590/S1516-18462009000100015.

19. Goulart BNG, Rocha JG, Chiari BM. Intervenção fonoaudiológica em grupo a cantores populares: estudo prospectivo controlado. J Soc Bras Fonoaudiol. 2012;24(1):7-18. http://dx.doi.org/10.1590/S2179-64912012000100004.

20. Caporossi C, Ferreira LP. Sintomas vocais e fatores relativos ao estilo de vida de professores. Rev CEFAC. 2011;13(1):132-9. http://dx.doi. org/10.1590/S1516-18462010005000099.

21. Andrade SR, da Fontoura DR, Cielo CA. Interrelações entre fonoaudiologia e canto. Música Hodie. 2007;7:83-98.
22. Colepicolo CR, Ferreira LP. A atuação conjunta entre professores de canto e Fonoaudiólogos: uma revisão da literatura. Per Musi. 2017:1-16.

23. Guimarães VC, Viana M, Barbosa M, Paiva ML, Tavares JA, Camargo LA. Vocal care: question of prevention and health. Cien Saude Colet. 2010;15(6):2799-803. PMid:20922288.

\section{Contribuição dos autores}

JCM delimitação do estudo, coleta de dados, análise de dados, redação do estudo; GM delimitação do estudo e revisão do estudo; $C P$ delimitação do estudo e revisão do estudo; MB delimitação do estudo, análise de dados, redação e revisão do estudo. 
Apêndice A. Questionário de conhecimento vocal para professores de canto

Questionário

DADOS DE IDENTIFICAÇÃO

NOME:

IDADE:

PROFISSÃO:

EM QUAL INSTITUIÇÃO TRABALHA:

1- Você costuma encaminhar para o Fonoaudiólogo o(a) aluno(a) que apresente dificuldades em agudos?

Sim $\square$ Não $\square$

2- Você costuma encaminhar para o Fonoaudiólogo o(a) aluno(a) que apresente algum tipo de dificuldade respiratória?

Sim $\square$ Não $\square$

3- Você costuma encaminhar para o Fonoaudiólogo o(a) aluno(a) que apresente queixa de voz rouca?

Sim $\square$ Não $\square$

4- Você costuma encaminhar para o Fonoaudiólogo o(a) aluno(a) que apresente alguma dificuldade de articulação?

Sim $\square$ Não $\square$

5- Você costuma encaminhar para o Fonoaudiólogo o(a) aluno(a) que relate queixa de falta de projeção?

Sim $\square$ Não $\square$

6- Você costuma encaminhar para o Fonoaudiólogo o(a) aluno(a) que apresente queixa de refluxo?

Sim $\square$ Não $\square$

7- Você costuma encaminhar para o Fonoaudiólogo o(a) aluno(a) que apresente queixa de cansaço ao falar por algumas horas seguidas?

Sim $\square$ Não $\square$

8- Você costuma encaminhar para o Fonoaudiólogo o(a) aluno(a) que só consegue cantar em alta intensidade?

Sim $\square$ Não $\square$

9- Você costuma encaminhar para o Fonoaudiólogo o(a) aluno(a) que relate pigarro, sensação de secura ou algum outro desconforto na garganta?

Sim $\square$ Não $\square$

10- Você sabia que queixa de rouquidão há mais de quinze dias pode ser sinal de tumor?

Sim $\square$ Não $\square$ 